\title{
A SINGLE-FORCE MODEL FOR THE 1975 KALAPANA, HAWAII, EARTHQUAKE
}

\author{
Holly K. Eissler ${ }^{1}$ and Hiroo Kanamori
}

Seismological Laboratory, California Institute of Technology, Pasadena

\begin{abstract}
A single force mechanism is investigated as the source of long-period seismic radiation from the 1975 Kalapana, Hawaii, earthquake $\left(\mathrm{M}_{\mathrm{S}}=7.1\right)$. The observed Love wave radiation pattern determined from the spectra of World-Wide Standard Seismograph Network and High Gain Long Period records at $100 \mathrm{~s}$ is two-lobed with azimuth, consistent with a near-horizontal single force acting opposite (strike $\sim 330^{\circ}$ ) to the observed displacement direction of the earthquake; this pattern is: inconsistent with the expected double-couple pattern. Assuming a form of the force time history of a one-cycle sinusoid, the total duration of the event estimated from Rayleigh waves at two International Deployment of Accelerometers stations is approximately $180 \mathrm{~s}$. The peak amplitude $\mathrm{f}_{\circ}$ of the time function is $1 \times 10^{15} \mathrm{~N}$ from amplitudes of Love and Rayleigh waves. The interpretation is that the bulk of the seismic radiation was produced by large-scale slumping of a large area of the south flank of Kilauea volcano. The single force is a crude representation of the effect on the earth of the motion of a partially decoupled large slide mass. Using the mass estimated from the tsunami generation area $(\sim$ $\left.10^{15}-10^{16} \mathrm{~kg}\right)$, the peak acceleration of the slide block $(0.1-1$ $\mathrm{m} \mathrm{s}^{-2}$ ) inferred from the seismic force is comparable with the acceleration due to gravity on a gently inclined plane. The slump model for the Kalapana earthquake is also more qualitatively consistent with the large horizontal deformation ( $8 \mathrm{~m}$ on land) and tsunami associated with the earthquake, which are difficult to explain with the conventional double-couple source model. The single-force source has been used previously to model the long-period seismic waves from the landslide accompanying the eruption of Mount St. Helens volcano, and may explain other anomalous seismic events as being due to massive slumping of sediments or unconsolidated material and not to elastic dislocation.
\end{abstract}

\section{Introduction}

Non-double-couple mechanisms have been investigated recently as source models for seismic events. The single force was invoked as a viable seismic source by Kanamori and Given [1982] to explain the long-period surface waves associated with the Mount St. Helens eruption sequence. They interpreted the force as the seismic signature of the massive landslide that occurred on the north slope of the volcano. Along other lines, non-double-couple mechanisms discovered during routine moment tensor inversions of earthquake data can be explained by such things as complexity in the rupture or intrinsically different source processes [Sipkin, 1986]. As the sensitivity and frequency range of seismographs continue to increase, we will be able to more frequently detect signals from geological phenomena other than elastic dislocations that occur abruptly enough to be seen as seismic events, such as mas-

\footnotetext{
${ }^{1}$ Now at Institute of Geophysics and Planetary Physics, Scripps Institution of Oceanography, University of California, San Diego, La Jolla.
}

Copyright 1987 by the American Geophysical Union.

Paper number 6B6225.

0148-0227/87/006B-6225\$05.00 sive sediment slides, or volcanic explosions. Previously, many such events may have been interpreted, by default, as conventional earthquakes (double couple).

In this paper, we show that the long-period seismic radiation from the large 1975 Kalapana, Hawaii, earthquake $\left(M_{S}=7.1\right)$ is best explained by a single-force model. The observed coseismic deformation and large tsunami amplitude associated with the earthquake are anomalous for an event of this magnitude. Several geologic studies have proposed a large-scale gravitational slump or landslide to explain observations of the earthquake. We propose that during a slump event, the upper slide block becomes essentially decoupled from the earth, producing an apparent single force. Other seismological studies of the earthquake have assumed the elastic dislocation source and have not addressed the question of whether the seismic radiation itself could be produced by massive slumping. Many examples of massive submarine slumps, located offshore of systems of normal faults flanking volcanic centers, are found on the Hawaiian Ridge, indicating that large-scale slumping can be a common mode of deformation in an oceanic volcanic regime.

This study uses some of the techniques of the Mount St. Helens analysis [Kanamori and Given, 1982]. Due to a limited data set, a study with the rigor of that analysis was not possible for the Kalapana earthquake. In 1975 when the earthquake occurred; the high-gain digital International Deployment of Accelerometers (IDA) and Global Digital Seismic Network (GDSN) networks were still in developmental stages. The analysis presented here uses mainly World-Wide Standard Seismograph Network (WWSSN) records and some supplemental data from the High Gain Long Period (HGLP) network, a prototype of the presentday Abbreviated Seismic Research Observatory (ASRO) stations of the GDSN network. Two early operating IDA stations provided additional long-period Rayleigh wave data.

\section{Previous Studies of the Kalapana Earthquake}

A sketch map of the relevant area of the island of Hawaii, showing the epicenter of the Kalapana earthquake, is given in Figure 1. An excellent observational summary of the earthquake was provided by Tilling et al. [1976], and deformations have been discussed by Lipman et al. [1985]. The accompanying tsunami has been described by Hatori [1976] and Cox [1980]. Seismic analyses of surface and body waves and implications were published by Ando [1979] and Furumoto and Kovach [1979].

The essential points of the above studies can be summarized as follows. The earthquake occurred on November 29,1975 , with $\mathrm{M}_{\mathrm{S}}=7.1\left(\mathrm{M}_{\mathrm{L}}=7.2\right)$, the largest instrumental magnitude reported to date for a Hawaiian earthquake. Hawaii Volcano Observatory (HVO) gave the location as $19^{\circ} 20^{\prime} \mathrm{N}, 155^{\circ} 02^{\prime} \mathrm{W}, \mathrm{h}=5-7 \mathrm{~km}$, origin time 14 47:40.4 UT Later studies determined the depth at $9 \mathrm{~km}$ [Crosson and Endo, 1981] and $10 \mathrm{~km}$ [Ando; 1979]. A foreshock of $\mathrm{M}_{\mathrm{L}}=5.7$ preceded the event. The earthquake affected most of the south flank of Kilauea volcano, between the southwest rift zone and the east rift zone. The large static deformations that were caused by the earthquake are shown in Figure 2. Coseismic subsidence was observed along $50 \mathrm{~km}$ of the south coast between the rift 


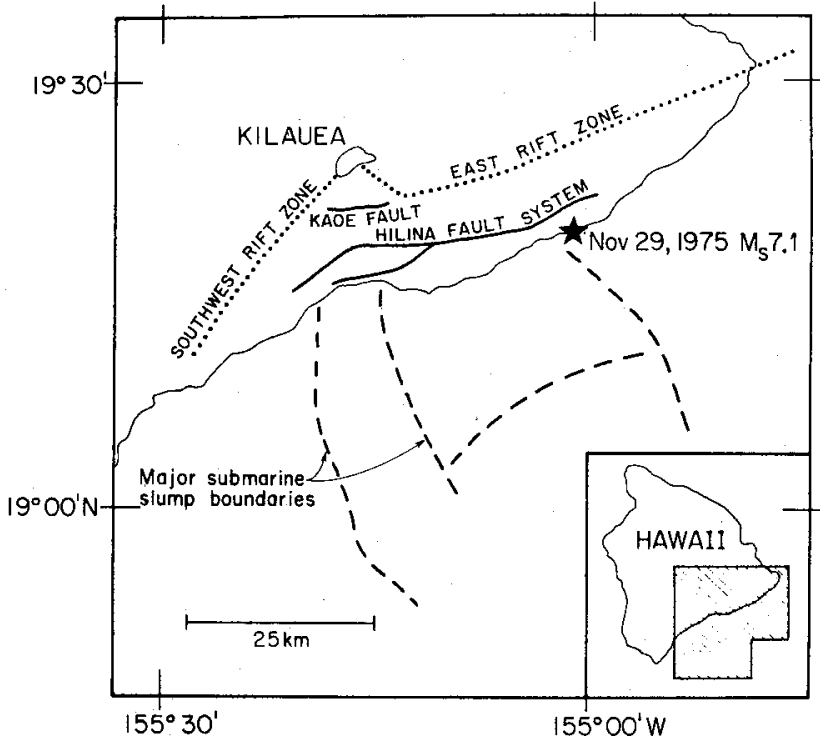

Fig. 1. Sketch map of the area of Hawaii involved in the Kalapana earthquake, adapted from Macdonald et al. [1983]. Outlines are shown of approximate boundaries of major submarine slumps built up during the extended history of the island.

zones; the largest subsidence was $3.5 \mathrm{~m}$ at Halape beach, about $30 \mathrm{~km}$ southwest of the epicenter. Observed horizontal extensions increased steadily seaward over the south flank, from about $1 \mathrm{~m}$ at the summit to $8 \mathrm{~m}$ at the coast; again, the maximum extension. was in the vicinity of Halape beach [Lipman et al., 1985]. Ground cracking was observed along $25 \mathrm{~km}$ of the Hilina fault system, with a maximum displacement of about $1.5 \mathrm{~m}$ downdropped to the south, which is consistent with the overall sense of motion on the Hilina faults. A severe tsunami reached a maximum height of $14.6 \mathrm{~m}$ at Halape beach, where two campers were killed. A small eruption broke out on the floor of Kilauea caldera half an hour after the origin time, and continued for 21 hours. Similar large earthquakes accompanied by tsunamis previously occurred on this part of the island in 1868 and (less certain) 1823.

The teleseismic $P$ wave fault plane solution resolves one steeply dipping $\left(80^{\circ}-90^{\circ}\right)$ nodal plane with a strike of about $\mathrm{N} 60^{\circ} \mathrm{E}$ (Figure 3 [from Ando, 1979]). The inferred low-angle nodal plane is the preferred fault plane, as it is more compatible with the deformation and tsunami observations and the aftershock pattern. The inferred slip direction was purely dip-slip, oriented $\mathrm{N} 150^{\circ} \mathrm{E}$. The seismic momènt was determined from surface waves to be between 1.2 and $1.8 \mathrm{x}$ $10^{27}$ dyn $\mathrm{cm}$. The earthquake produced an extremely complex sequence of body waves, indicating a complex source. A strong motion record at Hilo showed at least five subevents, for a total duration of $75 \mathrm{~s}$ [Rojahn and Morrill, 1977 .

The observations of the Kalapana earthquake described above indicate seaward displacement of a large block on a near horizontal plane. Previous studies of the earthquake propose either that the event was triggered by a growing compressional stress over the south flank due to steady magma injection in to the east rift zone [Ando, 1979; Furumoto and Kovach; 1979; Crosson and Endo, 1981] or that the driving force was the inherent gravitational instability of the poorly consolidated and growing volcanic pile [Nakamura, 1980]. The prevolcanic oceanic crust, located at about $7 \mathrm{~km}$ depth and lubricated by an accumulation of deep-sea sediments, has been suggested as the slide plane Furumoto and Kovach, 1978; Crosson and Endo, 1982; Lipman et al., 1985]. Swanson et al. [1976] noted that the entire south flank of Kilauea is mobile and had undergone extensions of several meters in the last century previous to the 1975 earthquake. On the basis of displacement measurements, seismicity, and field observations, they concluded that the zone of dilatation or "tear-away zone" separating the south flank from the remaining volcano is composed of the southwest rift zone; the east rift zone, and the Koae fault system (see Figure 1). In this view, the Hilina fault system is a shallow feature that bounds large superficial landslide blocks, which are a readjustment to a more deepseated slippage. However, Lipman et al. [1985]. proposed that the Hilina faults become listric at depth and join with the volcano-crust interface, providing a major locus for deep block rotations and slumps. In either case the Hilina fault system and associated slumps are thought to have been built up by repeated deformation events, some of which involved long-term extensions and some of which were seismic events such as the Kalapana earthquake.

\section{Double-Couple and Single-Force Radiation Patterns}

Ando [1979] constructed radiation patterns from the amplitudes of Love and Rayleigh surface waves from the Kalapana earthquake recorded on the WWSSN network. The observed Rayleigh wave pattern matches the theoretical pattern computed for a double-couple source with the same orientation as the $P$ wave first motion solution $\left(\delta=10^{\circ}, \lambda=-90^{\circ}\right.$, and azimuth $=60^{\circ}$, where $\delta$ and $\lambda$ are the dip and slip angles of the fault, respectively). The Love wave radiation pattern, on the other hand, is problematic. It was distinctly two-lobed, whereas the theoretical pattern for the double couple is four-lobed. Ando [1979] concluded that the expected second node was missing due to a lack of data in the critical azimuth. The two-lobed Love wave pattern was rotated $90^{\circ}$ with respect to the Rayleigh wave pattern.

In this section we discuss the theoretical radiation patterns generated by a double-couple source and a singleforce source. We will attempt to show from surface wave observations that the best model for the long-period source of the Kalapana earthquake is a near-horizontal single force, oriented opposite to the inferred slip direction. This is very similar to the source used to describe the longperiod surface waves associated with the May 18, 1980, eruption of Mount St. Helens. Kanamori and Given [1982] noted that the Love waves had a two-lobed radiation pattern which could not be explained by a double-couple source and that the Love wave pattern was rotated $90^{\circ}$

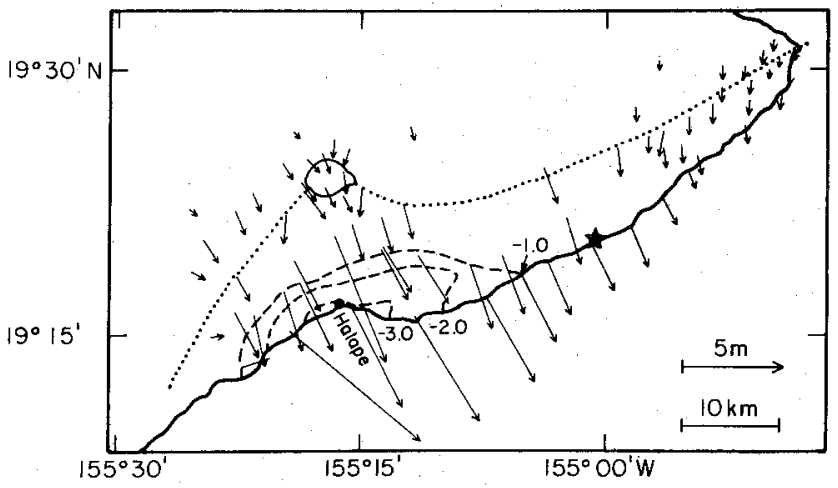

Figure 2. Map of the observed horizontal (vectors) and vertical (dashed contours) displacements associated with the Kalapana earthquake, adapted from Lipman et al. [1985]. The maximum displacements occurred about $30 \mathrm{~km}$ southwest of the epicenter (star). Horizontal displacements increase steadily seaward from $\sim 1 \mathrm{~m}$ at the summit of Kilauea to $\sim 8 \mathrm{~m}$ at Halape. Contours of vertical displacements are in meters. 


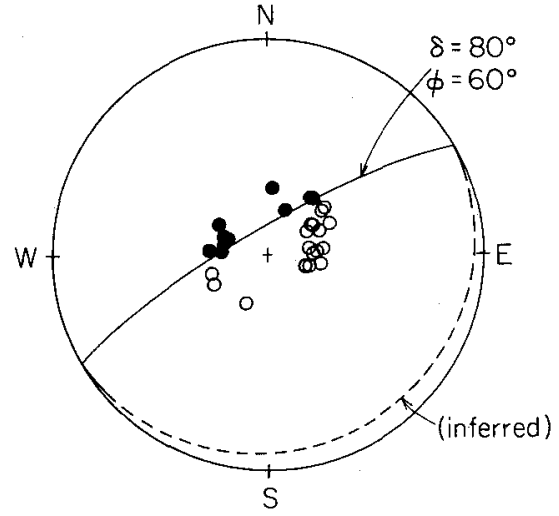

Fig. 3. Teleseismic $P$ wave first motion mechanism of the Kalapana earthquake, redrawn from Ando [1979]. The lowangle (dashed) nodal plane is inferred.

with respect to the Rayleigh wave pattern. They resolved a near-horizontal single force, with an azimuth opposite to the direction of motion of the large landslide that accompanied the eruption. The force was interpreted as the seismic expression of the landslide; as the mass slid downslope, its acceleration produced a force on the earth in the opposite direction. A more complete discussion of the use of the single force to represent this kind of block sliding is presented by Kanamori and Given [1982].

Love wave radiation patterns from the double-couple and single-force sources are shown in Figure 4. Figure 4a shows a map view of the epicenter, strike of the fault plane along the coast, and inferred slip direction of the earthquake (roughly perpendicular to the coast). Figure $4 \mathrm{~b}$ draws, in cross section, the double-couple force system corresponding to a low-angle normal fault. In the double- couple model the blocks on both sides of the fault plane are mechanically coupled to the body of the earth.

The theoretical spectrum of Love waves at the source for a double couple depends on the fault parameters $\delta, \lambda$, and $\phi$ as follows:

$$
\begin{aligned}
\hat{\mathrm{V}}_{\phi}(\omega)= & \mathrm{M}_{\mathrm{o}}\left[(\sin \lambda \sin \delta \cos \delta) \sin 2 \phi \mathrm{P}_{\mathrm{L}}^{(1)}(\mathrm{h}, \omega)\right. \\
& +(\cos \lambda \sin \delta) \cos 2 \phi \mathrm{P}_{\mathrm{L}}^{(1)}(\mathrm{h}, \omega) \\
& -\mathrm{i}(\cos \lambda \cos \delta) \sin \phi \mathrm{Q}_{\mathrm{L}}^{(1)}(\mathrm{h}, \omega) \\
& \left.+\mathrm{i}(\sin \lambda \cos 2 \delta) \cos \phi \mathrm{Q}_{\mathrm{L}}^{(1)}(\mathrm{h}, \omega)\right]
\end{aligned}
$$

where $P_{L}^{(1)}$ and $Q_{L}^{(1)}$ are the real-valued excitation functions given by Kanamori and Given [1981], $M_{0}$ is the seismic moment, $h$ is the source depth, $\omega$ denotes the angular frequency, $\phi$ is the azimuth of the station measured counterclockwise from the strike of the fault plane, and $\delta$ and $\lambda$ are the fault parameters dip and slip angle [Kanamori and Given, 1981]. Note that for any fault geometry save one, equation (1) has a four-lobed dependence on $\phi$, due to the $\cos 2 \phi$ and $\sin 2 \phi$ factors multiplying $\mathrm{P}_{\mathrm{L}}^{(1)}$. The exception is the case $\delta=0$ (a purely horizontal fault), where the coefficients of $\mathrm{P}_{\mathrm{L}}^{(1)}$ vanish.

The theoretical Love wave radiation pattern for a double-couple source, oriented to produce the displacement inferred for the Kalapana earthquake $\left(\delta=10^{\circ}, \lambda=-90^{\circ}\right.$, azimuth $=60^{\circ}$ ), is shown in Figure 4e.

Figure $4 \mathrm{c}$ shows a schematic model of the single-force source. Sliding motion is triggered by a sudden reduction of friction between the upper block and the slope. The reduction of friction causes the block to be accelerated downdip and reduces the downdip force exerted by the block on the slope. This sudden reduction of the downdip force is equivalent to a sudden application of an updip force on the slope. Since the block is decoupled mechanically from the slope, this updip force alone contributes to seismic radiation as a single force.

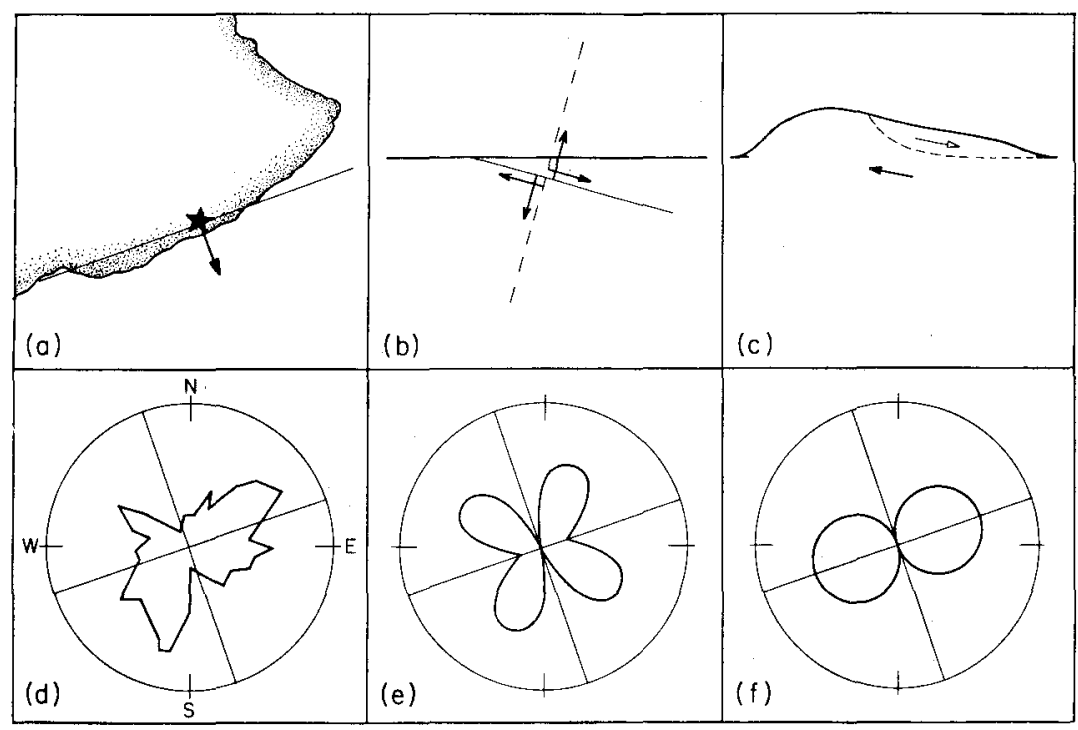

Fig. 4. Schematic description of the double force couple seismic source and the single-force seismic source. (a) Epicenter of the Kalapana earthquake, strike of the inferred fault plane approximately parallel to the coast, and direction of the observed maximum displacement (arrow). (b) In cross section, double force couple system corresponding to a normal fault dislocation on a low-angle fault plane. The auxiliary nodal plane is shown by the dashed plane. (c) Single force (lower arrow) on the earth produced by motion of the upper block, which slides (upper arrow) in the opposite direction. (d) Observed radiation pattern of Love waves from the Kalapana earthquake, redrawn from Ando [1979]. (e) Theoretical Love wave radiation pattern for a double couple consistent with the focal mechanism of the Kalapana earthquake; the pattern is four-lobed in azimuth. (f) Theoretical pattern for the single force (force strike, $330^{\circ}$ ). The pattern is two-lobed, with the radiation maximum in the azimuth perpendicular to the force direction. 
TABLE 1. Amplitude Spectra of $\mathrm{G}_{2}$ Waves, Corrected to Source

\begin{tabular}{lccc}
\hline $\begin{array}{c}\text { Station } \\
\text { Name }\end{array}$ & $\begin{array}{c}\mathrm{G}_{2} \text { Distance, } \\
\text { deg }\end{array}$ & $\begin{array}{c}\mathrm{G}_{2} \text { Azimuth, } \\
\mathrm{deg}\end{array}$ & $\begin{array}{c}\text { Amplitude at } \\
100 \mathrm{~s}, \mathrm{~cm} \mathrm{~s}\end{array}$ \\
\hline HGLP stations & & & 2.6 \\
CTA & 290.4 & 113 & 0.8 \\
CHG & 261.9 & 188 & 0.9 \\
KON & 259.7 & 204 & 1.7 \\
TLO & 244.8 & 286 & 0.6 \\
ZLP & 267.6 & & \\
WWSSN stations & & & 2.1 \\
TAU & & 39 & 2.9 \\
RIV & 278.5 & 44 & 3.0 \\
CTA & 286.4 & 59 & 1.7 \\
BAG & 290.4 & 104 & 1.2 \\
MAT & 280.4 & 122 & 1.0 \\
SHL & 299.7 & 122 & 0.9 \\
TAB & 258.9 & 161 & 0.8 \\
IST & 240.5 & 177 & 0.8 \\
NUR & 240.2 & 180 & 2.3 \\
ESK & 259.6 & 196 & 2.1 \\
MAL & 258.1 & 206 & 1.7 \\
SJG & 242.3 & 253 & \\
& 276.8 & &
\end{tabular}

For a unit single force deviating from horizontal by an angle $\alpha$ (measured positive upward), the theoretical Love wave source spectrum is given by

$$
\hat{\mathrm{V}}_{\phi}(\omega)=-\mathrm{i} \cos \alpha \sin \phi \frac{\mathrm{r}_{\mathrm{s}}}{\mathrm{N}} \mathrm{P}_{\mathrm{L}}^{(1)}(\mathrm{h}, \omega)
$$

where $r_{s}$ is the distance from the source to the center of the earth, $\mathrm{N}$ is the order number of the mode with angular frequency $\omega$, and $\phi$ is the azimuth of the station measured counterclockwise from the azimuth of the force [Kanamori and Given, 1982]. Note that equation (2) has a two-lobed dependence on $\phi$, with the nodal direction oriented in the direction of the force.

The theoretical Love wave pattern for a single force, oriented to produce the displacement inferred for the Kalapana earthquake, is shown in Figure $4 \mathrm{f}$. The force parameters are $\alpha=10^{\circ}$ with an azimuth of $330^{\circ}$, opposite to the direction of motion of the upper block.

The observed Love wave pattern is reproduced in Figure 4d from Ando [1979]. The observed pattern appears somewhat more consistent with the single-force source. Both sources fit the observed node at $150^{\circ}$. However, where the single-force pattern has its maximum at $60^{\circ}$, the double-couple pattern predicts a minimum. The observed radiation pattern of Love waves will be reexamined in a later section.

The effect of source depth is included in equations (1) and (2) through the excitation functions $P_{L}^{(1)}$ and $Q_{L}^{(1)}$. Their specific dependence on depth is determined by the eigenfunctions of the torsional modes of free oscillation, which are functions of the elastic properties of the medium. $\mathrm{P}_{\mathrm{L}}^{(1)}$ and $\mathrm{Q}_{\mathrm{L}}^{(1)}$ are proportional to the tangential particle velocity and stress respectively, evaluated at the source depth. Thus at the free surface (zero source depth) where the surface tractions vanish, the function $Q_{L^{(1)}}$ goes to zero, while $\mathrm{P}_{\mathrm{L}}^{(1)}$ stays finite. Recall from equation (1), the $\delta=0$ case (a purely horizontal fault) is the only double-couple orientation that eliminates the $2 \phi$ dependence, thus producing a two-lobed radiation pattern. "However, this geometry contains only the $\mathrm{Q}_{\mathrm{L}}^{(1)}$ function. Thus for a shallow, purely horizontal double couple, the seismic moment would have to be very large to produce appreciable Love wave amplitudes. Using a source depth of $10 \mathrm{~km}$, Ando
[1979] showed that as the fault plane dip approaches horizontal $\left(\delta \leq 10^{\circ}\right)$, the seismic moment required to produce the Love wave amplitudes observed from the Kalapana earthquake becomes so large that it is inconsistent with the observed static deformation.

The $P$ wave radiation pattern for a double couple is most simply represented by the quadrant focal mechanisni figure (for example, Figure 3). Two nodal planes divide the focal sphere into dilatational and compressional quadrants. A single force in a whole space will have only one nodal plane, perpendicular to the force, separating the focal sphere. into two regions of dilatational and compressional motion. The observed teleseismic first-motion data (Figure 3) identifies only one nodal plane and thus is consistent with either a double couple or a single-force source. However, first motions from the local Hawaiian Volcano Observatory (HVO) network weakly suggest a quadrant distribution [Furumoto and Kovach, 1979; Crosson and Endo, 1981]. This is not necessarily inconsistent with an overall long-period single-force source; in the first few seconds of the event the mechanism may be indistinguishable from a double couple.

\section{Long-Period Love Wave Radiation Pattern}

In this section we carefully reexamine the azimuthal dependence of Love wave amplitudes at longer periods. The seismic stations used are listed in Table 1 . Seven of the 12 WWSSN stations chosen had been used by Ando [1979]. In addition, Love wave data from five HGLP stations were used. Although Ando [1979] used amplitudes of $\mathrm{G}_{1}, \mathrm{G}_{2}$, and $\mathrm{G}_{3}$ waves, we limited the data set to the $\mathrm{G}_{2}$ passage only. In some cases, $G_{1}$ was contaminated by multiple $S$ phases, and the $G_{3}$ passage was at noise level for most of the stations. For each station, the two horizontal component seismograms were windowed between velocities of 4.6 and $4.0 \mathrm{~km} \mathrm{~s}^{-1}$ for the $\mathrm{G}_{2}$ distance, digitized, and rotated into transverse seismograms. The rotated HGLP seismograms are shown in Figure 5, and the WWSSN seismograms are shown in Figure 6. Although each record shows a clear $G_{2}$ wave train, the maximum amplitudes can occur at different periods, or different parts of the wave train. This is particularly true for the WWSSN records. Note that Ando's 


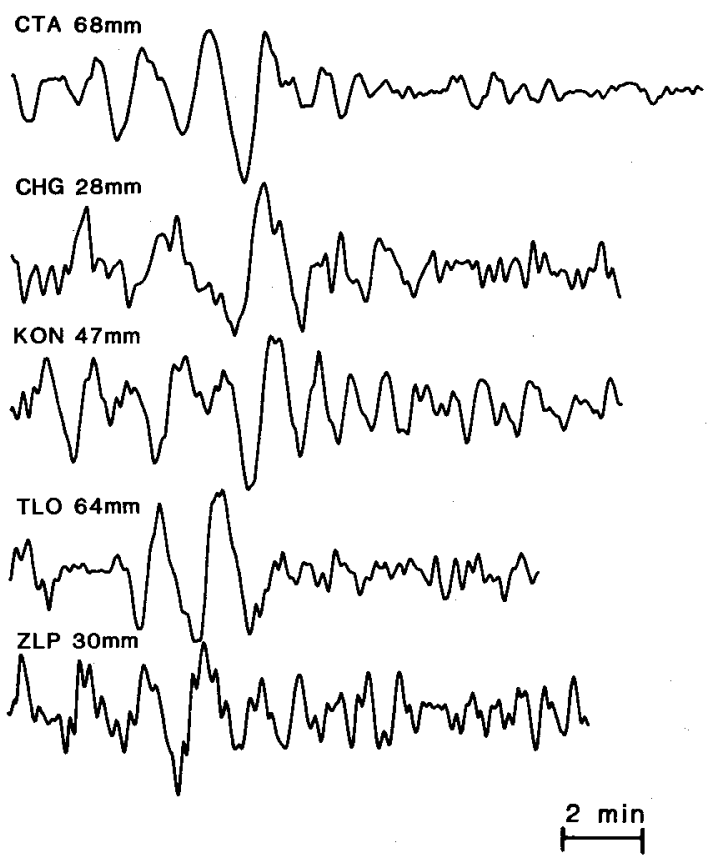

Fig. 5. Observed $\mathrm{G}_{2}$ passages of Love waves from HGLP stations. The maximum peak-to-peak amplitudes in $\mathrm{mm}$ of paper record, equalized to an instrumemt gain of 1000 , are shown above the traces.

[1979] radiation pattern was made from the maximum time domain amplitudes. For a more precise measure of signal amplitude, each wave train was Fourier transformed, and the amplitudes were examined as a function of period.

The observed source amplitude spectrum $\left|\hat{V}_{\phi}(\omega)\right|$ was obtained from the spectrum of the seismogram by correcting for propagation effects and the instrument response. This can be written as

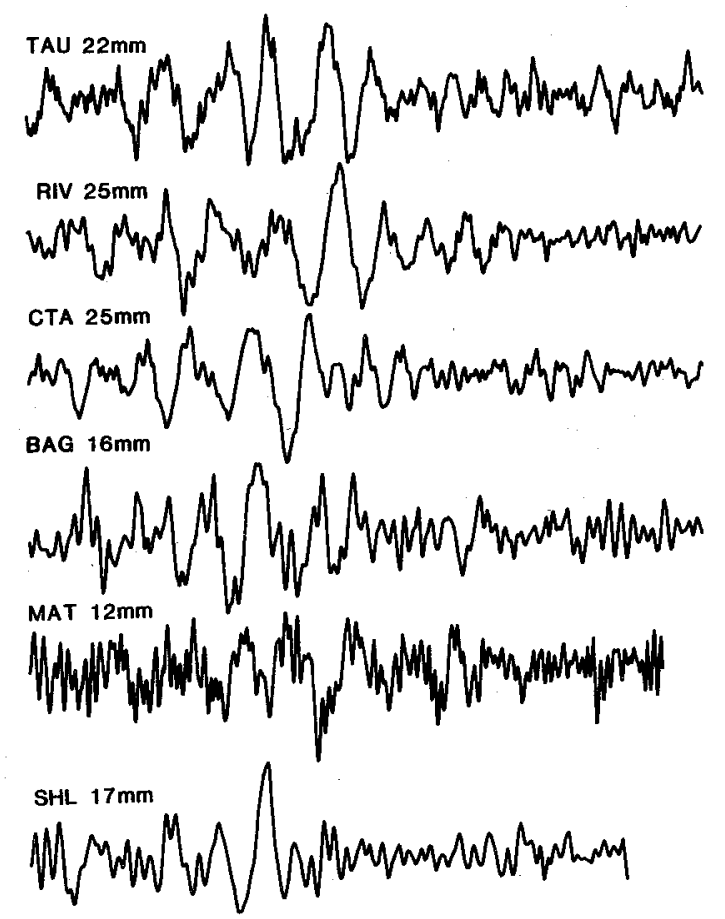

$$
\left|\hat{\mathrm{V}}_{\phi}(\omega)\right|=\hat{\mathrm{S}}(\omega) \sqrt{\sin \Delta} \exp \left(\frac{\omega \Delta_{\mathrm{km}}{ }^{\prime}}{2 \mathrm{QU}}\right) / \hat{\mathrm{I}}(\omega)
$$

where $\hat{\mathbf{S}}(\omega)$ is amplitude spectrum of the observed transverse seismogram, $\Delta$ is the source-to-station distance, $\Delta_{\mathrm{km}}{ }^{\prime}$ is the $\mathrm{G}_{2}$ propagation distance in $\mathrm{km}, \mathrm{Q}$ the attenuation factor, $U$ the group velocity, and $\hat{\mathrm{I}}(\omega)$ represents the amplitude response of the instrument. Values for $Q$ and $U$ were taken from Kanamori [1970]. Given the limited band of the WWSSN instrument, $100 \mathrm{~s}$ was the longest period at which the spectra could be read with confidence. Values of $\left|\hat{\mathrm{V}}_{\phi}\right|$ at a period of $100 \mathrm{~s}$ are listed in Table 1 ; Figure 7 shows $\left|\hat{\mathrm{V}}_{\phi}\right|$ at $100 \mathrm{~s}$ plotted versus azimuth.

The observed pattern is two-lobed in azimuth, with a clear radiation maximum at $60^{\circ}$ and a node at $150^{\circ}$. Both the static deformation pattern and the teleseismic focal mechanism of Kalapana earthquake imply a slip direction with azimuth $150^{\circ}$. The single force on the earth resulting from this slip direction would be oriented in the opposite azimuth, $330^{\circ}$. The observed Love wave radiation pattern is consistent with that of a single-force oriented at $330^{\circ}$; nodes lie along the force direction, and maxima lie in the perpendicular directions. The two-lobed nature of the observed pattern itself precludes any realistic double-couple source; in addition, the observed maxima and nodes are located as expected for a single-force source that is consistent with the field observations. The radiation pattern from the spectral amplitudes of long-period Love waves thus supports the single-force model.

\section{Rayleigh Wave Analysis}

Long-period Rayleigh wave data from two IDA stations that were operating at Canberra, Australia, and Naña, Peru, provide additional information on the source of the Kalapana earthquake. In particular, by forward modeling of the waveforms assuming a single-force source, the time history and the amplitude of the force can be estimated. The $R_{2}$ and $R_{3}$ phases at both stations were used; $R_{1}$ was offscale. Unfortunately, CAN is very near to the node of
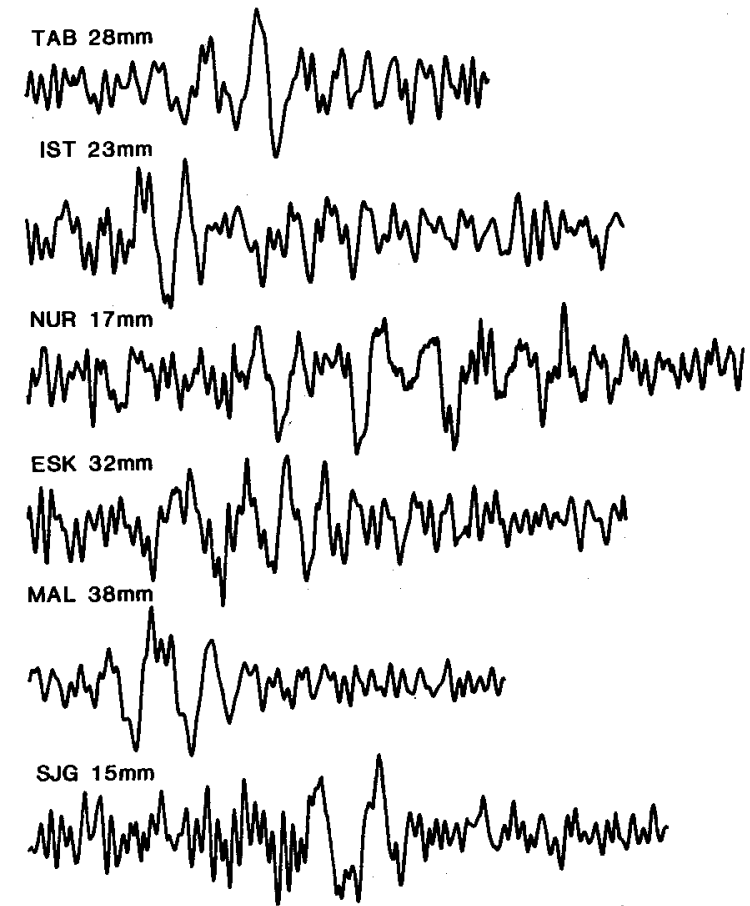

Fig. 6. Observed $\mathrm{G}_{2}$ passages of Love waves from WWSSN stations. 


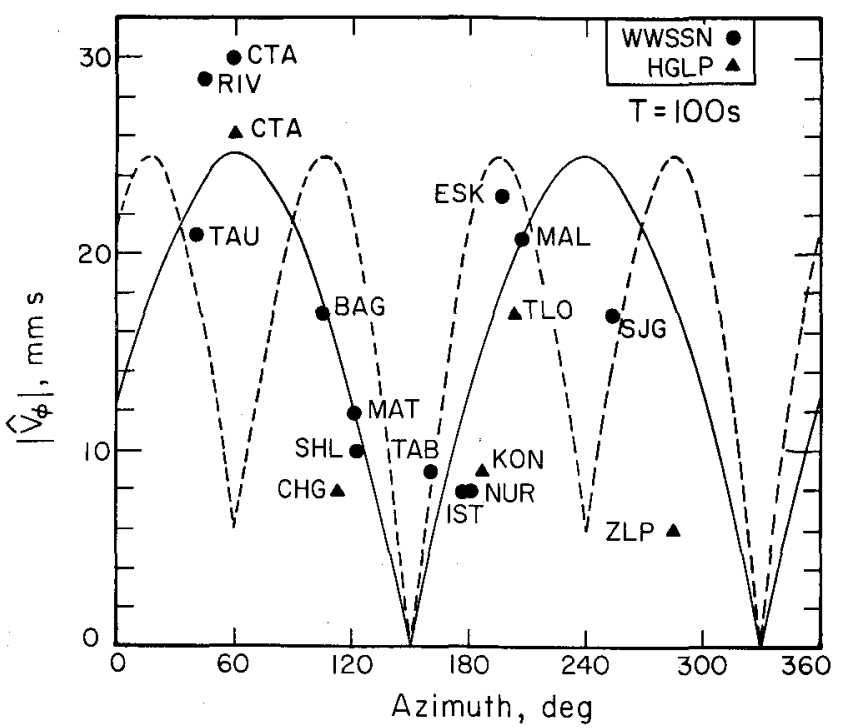

Fig. 7. Observed source spectrum amplitudes versus azimuth of Love waves at a period of $100 \mathrm{~s}$. Solid line is the theoretical radiation pattern of a single-force source, and dashed line is that of a double couple. The maximum at $60^{\circ}$ corresponds to a predicted maximum for the single force but a minimum for the double couple. Both sources predict the observed node at $150^{\circ}$.

the Rayleigh wave radiation pattern for the force orientation determined above ( $16^{\circ}$ from the node); NNA is somewhat better, $45^{\circ}$ from the node.

Vertical component synthetic Rayleigh wave seismograms can be calculated by summing over spheroidal oscillations excited by a single force, as described by Kanamori and Given [1982]. The ground motion is given by

$\mathrm{U}_{\mathrm{r}}(\overrightarrow{\mathrm{r}}, \mathrm{t})=\sum_{\mathrm{N}} \mathrm{r}_{\mathrm{s}} \mathrm{K}_{2}\left[-\frac{\mathrm{y}_{1}\left(\mathrm{r}_{\mathrm{s}}\right)}{\mathrm{y}_{3}\left(\mathrm{r}_{\mathrm{s}}\right)} \sin \alpha \mathrm{P}_{\mathrm{N}}{ }^{\mathrm{o}}-\cos \alpha \cos \phi \mathrm{P}_{\mathrm{N}}{ }^{1}\right] \cos \omega_{\mathrm{N}^{\mathrm{t}}}$

where $\alpha$ and $\phi$ define the force geometry, $\mathrm{K}_{2}$ is the excitation function defined by Kanamori and Cipar [1974], $\mathrm{P}_{\mathrm{N}}{ }^{\circ}$ and $\mathrm{P}_{\mathrm{N}}{ }^{1}$ are Legendre functions, $\mathrm{y}_{1}$ and $\mathrm{y}_{3}$ are factors proportional to displacements specified by the order number $\mathrm{N}, \mathrm{r}_{\mathrm{s}}$ denotes the distance from the center of the earth to the source, and $\omega_{N}$ is the eigenfrequency of the mode with order number N. Equation (4) assumes a step function source in time. The calculated seismogram $\mathrm{S}_{\mathrm{r}}(\mathrm{t})$ for a delta function source in time is then given by $\mathrm{dU}_{\mathrm{r}}(\mathrm{t}) / \mathrm{dt}$ convolved with the IDA instrument response.

The $R_{2}$ and $R_{3}$ phases at both stations seemed to be depleted in energy at periods less than about $100 \mathrm{~s}$, and thus synthetic seismograms for a delta function time dependence were too short period to explain the data. In modeling the Mount St. Helens landslide, Kanamori and Given [1982] originally assumed a smooth, half-cosine time function with a peak force $\mathbf{f}_{o}$ and a time constant $\tau$ :

$$
f_{o} s(t)= \begin{cases}1 / 2 f_{o}(1-\cos (\pi t / \tau)) & 0 \leq t \leq 2 \tau \\ 0 & t>2 \tau\end{cases}
$$

They found that this time function generally fit both the time domain waveforms and the source spectra retrieved from the data for $\tau \sim 75 \mathrm{~s}$. Note that the quantity $\mathrm{f}_{\mathrm{o}} \mathrm{s}(\mathrm{t})$ is always positive for this time function. Subsequent work was done using intermediate period data from Mount St. Helens (i.e., SRO and ASRO $R_{1}$ and $G_{1}$ waves), where the time history of the force was obtained by direct deconvolution over a limited frequency band [Kanamori et al., 1984]. This revealed an "overshoot," or negative portion to the time function, which can be interpreted as deceleration of the slide mass. The total time duration of the Mount St. Helens source with the overshoot included is $200 \mathrm{~s}$.

The sampling rate of the IDA network at the time of the Kalapana earthquake was $20 \mathrm{~s}$, which makes it difficult to stably resolve signal at periods of $50-100 \mathrm{~s}$ by direct deconvolution. Instead, we estimate the time history of the source by assuming a time function similar in form to that resolved from the Mount St. Helens deconvolution, a simple one-cycle sine wave with half-period $\tau$.

$$
\mathrm{f}_{\mathrm{o}} \mathrm{s}(\mathrm{t})= \begin{cases}\mathrm{f}_{\mathrm{o}} \sin (\pi \mathrm{t} / \tau) & 0 \leq \mathrm{t} \leq 2 \tau \\ 0 & \mathrm{t}>2 \tau\end{cases}
$$

Figure 8 shows a suite of synthetic seismograms made for this time history with varying values of $\tau$ for the $R_{2}$ phase at NNA, with the observed waveform at the top of the figure. The best fit of the overall period content of the data occurs for $\tau \sim 90 \mathrm{~s}$, so that the total duration of the source with the deceleration phase is $180 \mathrm{~s}$. Figure 9 shows that the assumed time history, with $\tau=90 \mathrm{~s}$, is successful in matching the other observed Rayleigh waveforms as well. The peak force amplitude $f_{0}$ can be obtained by comparing the amplitudes of the synthetic seismograms, made for a reference force size, to those of the observed records. The peak force amplitudes determined from the four waveforms are given in Table 2. The force sizes range from $1.1 \times 10^{15}$ $\mathrm{N}$ to $2.0 \times 10^{15} \mathrm{~N}$. The average value is $1.6 \times 10^{15} \mathrm{~N}$, with a standard deviation of $0.4 \times 10^{15} \mathrm{~N}$. The higher values of $f_{0}$ were obtained from the CAN phases, which is very close to the node because the synthetic amplitudes are very small there; the values from NNA are considered more accurate. Note that this value of $f_{o}$ is valid only if the event has the specific time dependence $s(t)$ assumed in the calculation; if the actual time history were different, the estimate of $f_{o}$ would change accordingly.

An independent estimate of $f_{\circ}$ can be obtained from the observed Love wave spectral amplitudes found in the previous section. The theoretical source spectrum of Love waves, $\hat{\mathrm{V}}_{\phi}(\omega)$, for a unit force and a step time dependence is given

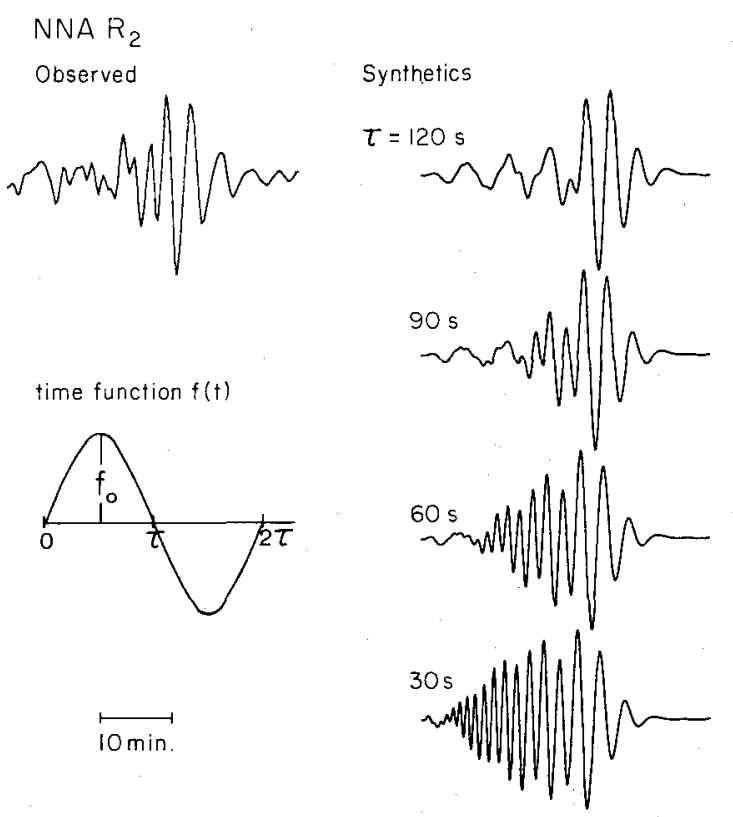

Fig. 8. Comparison of the observed Rayleigh wave $\left(R_{2}\right.$ passage) at the IDA station NNA, with a suite of synthetic seismograms made with the force time function, for varying values of the time constant $\tau$. The best match occurs at $\tau=$ $90 \mathrm{~s}$. 

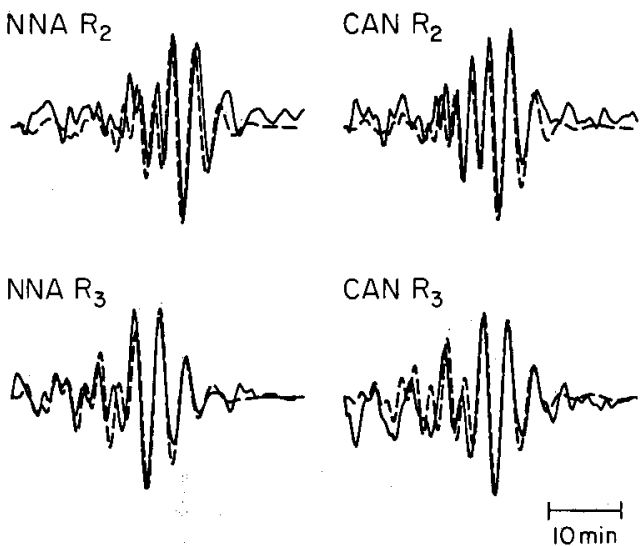

Fig. 9. Synthetic (dashed) and observed seismograms for $R_{2}$ and $\dot{R}_{3}$ passages at both IDA stations with $\tau=90 \mathrm{~s}$. The vertical scale is arbitrary.

by equation (2). The theoretical spectrum for a source with a different time dependence will be given by the product of equation (2) with the transform of the time function. The Fourier transform of the assumed time function (equation (6)) is given by

$$
\hat{\mathrm{s}}(\omega)=2 \pi \mathrm{i} \tau \frac{\sin \omega \tau}{\pi^{2}-(\omega \tau)^{2}} \mathrm{e}^{-\mathrm{i} \omega \tau}
$$

Equation (2) was evaluated for a period of $100 \mathrm{~s}$, a source depth of $10 \mathrm{~km}$, a time constant $\tau$ of $90 \mathrm{~s}$, and the geometry inferred for the single force. The modulus was then multiplied by the modulus of equation (7) with $\tau=$ $90 \mathrm{~s}$ to arrive at the theoretical source amplitude of $100 \mathrm{~s}$ waves for a source with the time history in equation (6). (A factor of $\omega$ is needed to convert equation 2 in to a delta function time dependence). We compare the theoretical value at the radiation maximum $\left(0.27 \mathrm{~mm}\right.$ s at $60^{\circ}$ azimuth for an assumed unit force size of $1 \times 10^{13} \mathrm{~N}$ ) with that from the observed Love wave pattern (approximately $25 \mathrm{~mm}$ s at $60^{\circ}$ azimuth; see Figure 7). The resultant peak force size $f_{o}$ is $9.3 \times 10^{14} \mathrm{~N}$, in good agreement with the average value of $1.6 \times 10^{15} \mathrm{~N}$ determined from the Rayleigh wave data. The force estimates from the Rayleigh wave data are likely to be biased upward because the stations were preferentially distributed near the node, whereas the Love wave estimates are derived from a more uniform azimuthal distribution, so that we prefer the lower value of $\sim 1 \times 10^{15} \mathrm{~N}$ as the more reliable estimate of the peak force size. Thus from the long-period surface wave data the peak force size involved in the Kalapana event can be constrained to be of the order $1 \times 10^{15} \mathrm{~N}$, with an overall duration of about 3 min. In comparison, the peak force from the Mount St. Helens event was $\sim 1 \times 10^{13} \mathrm{~N}$.

The source spectrum for Rayleigh waves excited by a single force source with time function $f_{o} s(t)$ is given by
Period, $\mathrm{s}$

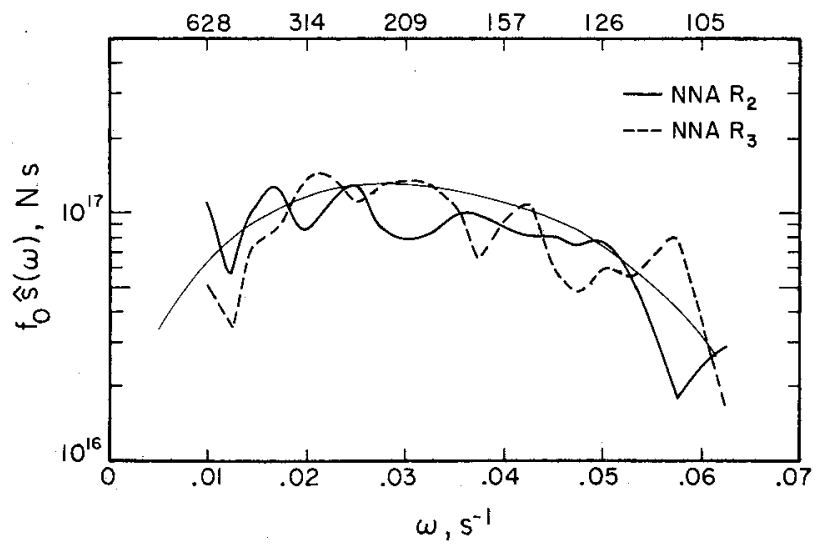

Fig. 10. Amplitude spectra of the force time history retrieved from the $R_{2}$ (solid) and $R_{3}$ (dashed) passages at NNA, compared with the amplitude spectrum of the force time history assumed in the modeling (thin line).

$$
\hat{\mathrm{V}}_{\mathrm{r}}(\omega)=\frac{\mathrm{ir}_{\mathrm{s}}}{\mathrm{N}} \mathrm{P}_{\mathrm{R}}{ }^{(1)} \omega \mathrm{f}_{\mathrm{o}} \hat{\mathrm{s}}(\omega)\left[\frac{\sin \alpha}{\mathrm{N}} \frac{\mathrm{y}_{1}\left(\mathrm{r}_{\mathrm{s}}\right)}{\mathrm{y}_{3}\left(\mathrm{r}_{\mathrm{s}}\right)}+i \cos \alpha \cos \phi\right]
$$

where $P_{R}{ }^{(1)}$ is the excitation function given by Kanamori and Given [1981]. For the Kalapana earthquake the force is near horizontal $(\alpha \sim 0)$, so

$$
\hat{\mathrm{V}}_{\mathrm{r}}(\omega) \approx-\frac{\mathrm{r}_{\mathrm{s}}}{\mathrm{N}} \mathrm{P}_{\mathrm{R}}(1) \omega \mathrm{f}_{\mathrm{o}} \hat{\mathrm{s}}(\omega) \cos \phi
$$

Thus the amplitude spectrum of the time function is given by

$$
\left|\mathrm{f}_{\mathrm{o}} \hat{\mathrm{s}}(\omega)\right| \approx\left|\frac{\hat{\mathrm{V}}_{\mathrm{r}}(\omega) \mathrm{N}}{\omega \mathrm{r}_{\mathrm{s}} \mathrm{P}_{\mathrm{R}}{ }^{(1)}} \frac{1}{\cos \phi}\right|
$$

We can check the assumption for the time function of the Kalapana earthquake by comparing the right hand side of equation (10) with the modulus of equation (7). The factor $\left|\hat{V}_{\mathrm{r}}(\omega)\right|$ is obtained from the observed spectra as shown in equation (3), with the values of $Q$ and $U$ now being those of the spheroidal modes. We calculated $\left|f_{o} \hat{s}(\omega)\right|$ from equation (10) using the NNA $R_{2}$ and $R_{3}$ phases. These are shown with the amplitude spectrum of the assumed force time history at $\tau=90 \mathrm{~s}$ in Figure 10 . The CAN record was not used due to its nodal nature. Although the $R_{2}$ and $R_{3}$ curves are plotted on the same vertical scale and should be equal since all propagation effects are removed, the vertical scale for the assumed force spectrum is arbitrary. The observed spectra generally match the shape of the assumed spectrum, which varies with $\omega$ as $\sin \omega \tau /\left(\pi^{2}-\omega^{2} \tau^{2}\right)$. However, even within the extended band range of the IDA data (Figure 10 shows spectra from periods of 105-628 s), we see only a limited

TABLE 2. Station List, Rayleigh Waves

\begin{tabular}{lccccc} 
Station & Phase & $\begin{array}{c}\text { Distance, } \\
\text { deg }\end{array}$ & $\begin{array}{c}\text { Azimuth, } \\
\text { deg }\end{array}$ & $\begin{array}{c}\text { Observed Peak-to-Peak } \\
\text { Amplitude, counts }\end{array}$ & $\begin{array}{c}\text { Peak Force } \\
\text { Size, dynes }\end{array}$ \\
\hline & & & & & $1.1 \times 10^{20}$ \\
NNA & $\mathrm{R}_{2}$ & 227.0 & 285.1 & 678 & $1.5 \times 10^{20}$ \\
NNA & $R_{3}$ & 443.0 & 105.1 & 441 & $2.0 \times 10^{20}$ \\
CAN & $R_{2}$ & 284.1 & 44.4 & 193 & $1.6 \times 10^{20}$ \\
CAN & $R_{3}$ & 436.0 & 224.4 & &
\end{tabular}


portion of the amplitude spectra of the assumed force history. Theoretically, because the slide mass has no final velocity, the time integral of the force $f_{o} s(t)$ over the duration of the event should equal zero. The time function need not have the simple form assumed in the modeling to meet this criterion; for example, the deceleration phase could have a longer duration and smaller peak amplitude. In any case, however, the source spectrum should go to zero at zero frequency. This is not the case for the double-couple source, where the source spectrum has a nonzero value at zero frequency, which is the seismic moment $M_{0}$.

A trend toward zero at long periods is difficult to see in Figure 10 because the spectrum of the assumed force with $\tau=90 \mathrm{~s}$ is so broad; for example, the spectral amplitude does not fall to $1 / 3$ its maximum value until $\mathrm{T} \sim 900$ s. However, the observed spectra suggest the beginning of a downward trend at longer periods, and the overall match with the assumed spectrum in general corroborates the choice of the time dependence in equation (6). The peak value achieved by the observed force spectra is $\sim 1.3 \times 10^{17}$ $N$ s. Kanamori and Given [1982] found a peak spectral amplitude for the Mount St. Helens landslide of $5 \times 10^{14} \mathrm{~N}$ s, approximately 260 times smaller.

\section{Discussion}

\section{Slumping as a Seismic Event}

We raise the question of whether the events that build the massive slump features observed on the Hawaiian Ridge happen on the time scale of seismic events, or by slower, nonseismic creeping or flowing deformation. After the Kalapana earthquake, several researchers asked whether a standard "tectonic" (i.e., elastic dislocation) event could have produced the large tsunami and observed displacement, or whether they were actually produced by landsliding motion triggered by an earthquake. To our knowledge, no study previously addressed the question of whether the seismic radiation itself was caused by landsliding motion, i.e., whether the event could be described by a different force system than that used for tectonic earthquakes. Apart from arguments about the scale of coseismic displacement or time durations possible in a moderate sized double-couple elastic dislocation source, the distingushing criteria between the single-force and double-couple sources must come from the dynamic wave fields. As discussed above, the Love wave radiation pattern is one of the best discriminators. We also showed that both the Love and Rayleigh wave amplitudes can be explained by the same force magnitude, and as we discuss later, this magnitude is roughily consistent with the estimated mass involved in the slump event. The source time function of the Kalapana earthquake may have an acceleration and deceleration phase, as was discovered for the Mount St. Helens landslide.

From their estimates of seismic moment, Ando [1979] calculated a fault slip of $3.7-5.5 \mathrm{~m}$, and Furumoto and Kovach [1979] calculated a smaller fault slip of $1.4 \mathrm{~m}$. The observed maximum coseismic surface displacements were 3 $\mathrm{m}$ subsidence and $8 \mathrm{~m}$ horizontal seaward extension [Lipman et al., 1985]. The horizontal value increased steadily over the south flank from $1 \mathrm{~m}$ at the summit of Kilauea to $8 \mathrm{~m}$ at the coast and probably reached a larger value undersea. It is difficult to explain the observed surface deformations by a fault offset of a few meters, but landsliding or slumping could easily produce these displacements. The tsunami also implies that landsliding played a major role in the seismic event. Ando [1979] found that the maximum seafloor uplift resulting from the fault model is $\mathbf{0 . 5}$ $m$, which is too small to explain the observed tsunami amplitude. Hatori [1976] also noted that the tsunami magnitude was anomalously large compared to the earthquake magnitude. These observations imply that a process other than the seafloor deformation caused by motion on a buried fault was involved in the generation of the tsunami.

In addition to the Mount St. Helens landslide and the Kalapana earthquake, the single-force model appears applicable to at least one other unusual seismic event. The magnitude 7.2 earthquake that occurred in 1929 on the Atlantic continental slope near Grand Banks, Newfoundland, Canada, is well known for causing breaks in ocean bottom communication cables up to $580 \mathrm{~km}$ seaward of the epicenter. The delay time between the earthquake origin time and the cable breaks systematically increased with distance from the epicenter, from nearly coincident close by the epicenter, to 13 hours for the farthest break. This led to the conclusion that the cable breaks were caused by a large turbidity current (suspension flow) induced by the earthquake [Heezen and Ewing, 1952]. However, within a distinct area up to $100 \mathrm{~km}$ seaward of the epicenter, the cable breaks occurred within one minute of the earthquake. Heezen and Drake [1964] differentiated the quicker breaks in this region as being due to sediment slumps and landslides and not the turbidity current. The area experiencing the quick breaks is about $100 \mathrm{~km} \mathrm{x} 150 \mathrm{~km}$. With seismic reflection profiling, Heezen and Drake [1964] found several subsurface inclined disrupted boundaries in this region, with a major surface that they identified as the primary sole of the slump about $1 \mathrm{~km}$ under the ocean bottom. H. S. Hasegawa and H. Kanamori (Source mechanism of the magnitude 7.2 Grand Banks earthquake of November 1929: Double couple or submarine landslide? submitted to the Bulletin of the Seismological Society of America, 1986) have investigated seismic records from the earthquake, and their results support a near-horizontal single-force source with an azimuth opposite the direction of slumping. Their estimate of the force size is the same order of magnitude as the source of the Kalapana event. The single force may also be a more appropriate source model for events designated "tsunami earthquakes", whose long-period seismic radiation and associated tsunamis are anomalously large compared with their $\mathrm{M}_{\mathrm{S}}$ magnitudes [Kanamori, 1972].

\section{Inferred Source Parameters for the Kalapana Earthquake}

From the seismic force time history found above, the acceleration of the slide block with mass $M$ is

$$
\mathrm{a}(\mathrm{t})=\frac{\mathrm{f}_{\mathrm{o}}}{\mathrm{M}}\left(\sin \frac{\pi \mathrm{t}}{\tau}\right)
$$

where $f_{o}$ is approximately $1 \times 10^{15} \mathrm{~N}$. This is a simplification of a more physical case where the mass involved in the slide is also a function of time. The velocity and displacement functions are then

$$
\begin{aligned}
& \mathrm{v}(\mathrm{t})=\frac{\mathrm{f}_{\mathrm{o}} \tau}{\mathrm{M} \pi}\left(1-\cos \frac{\pi \mathrm{t}}{\tau}\right) \\
& \mathrm{x}(\mathrm{t})=\frac{\mathrm{f}_{\mathrm{o}} \tau}{\mathrm{M} \pi}\left(\mathrm{t}-\frac{\tau}{\pi} \sin \frac{\pi \mathrm{t}}{\tau}\right)
\end{aligned}
$$

The forms of these functions are shown in Figure 11. If the deceleration phase of $a(t)$ has a more trailing form than the sine function, shown by the dashed line in Figure 11a, then $v(t)$ and $x(t)$ will also change as shown.

A range of the mass $M$ of the slide block can be estimated from the dimensions of the tsunami source areas, which vary from $2200 \mathrm{~km}^{2}$ [Hatori, 1976] to $700 \mathrm{~km}^{2}$ [Cox, 

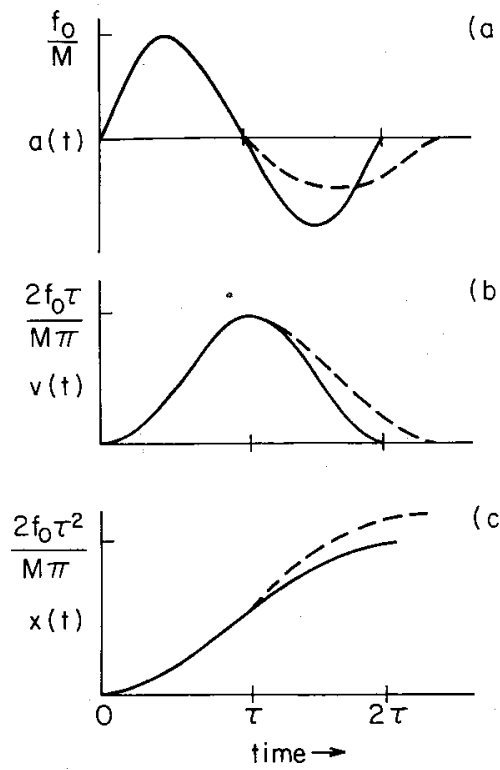

Fig. 11. (a)Acceleration history of the slide mass corresponding to the assumed force time history. The dashed line indicates an alternative time history, in which the deceleration phase is longer than the acceleration phase but the peak deceleration is smaller, so that the net time integral is zero. (b) Velocity function inferred from (Figure 11a). (c) Displacement function inferred from (Figure 11b).

1980]. Ando [1979] estimated a range between 800 and 2000 $\mathrm{km}^{2}$. If a wedge-shaped volume $\mathrm{V}$ extending to a slide plane at $7 \mathrm{~km}$ depth is assumed, with an effective density $\rho_{\mathrm{e}}$ of $1.7 \mathrm{~g} \mathrm{~cm}^{-3}$ to account for the buoyancy effect of the water, $\mathrm{M}$ ranges from $4 \times 10^{15} \mathrm{~kg}$ to $1.3 \times 10^{16} \mathrm{~kg}$. If the slide is a more surficial feature with a thickness of $1 \mathrm{~km}$, the mass range decreases to $6 \times 10^{14} \mathrm{~kg}$ to $1.9 \times 10^{15} \mathrm{~kg}$. For comparison, the estimated mass of the Mount St. Helens landslide was much smaller, $5 \times 10^{12} \mathrm{~kg}$.

As an overall mass range, we use $10^{15}-10^{16} \mathrm{~kg}$. The peak acceleration for the slide mass inferred from the seismic force is then $0.1 \mathrm{~m}-1 \mathrm{~m} \mathrm{~s}^{-2}$. This is comparable with the acceleration due to gravity on a gently inclined plane $(0.85$ $\mathrm{m} \mathrm{s} \mathrm{s}^{-2}$ for $\alpha=5^{\circ}$ ). Assuming the (functions for velocity and displacement in equations (12) and (13) with $\tau=90 \mathrm{~s}$, the inferred maximum velocity $v_{\max }$ of the slide is $5.7-57 \mathrm{~m} \mathrm{~s}^{-1}$ achieved at $t=\tau$. The inferred final displacement $x_{\max }$ is 260-2600 $\mathrm{m}$. The final displacement depends on the time constant $\tau$ as $\tau^{2}$, so that if $\tau$ is somewhat smaller, say $50 \mathrm{~s}$, the displacement for the larger mass estimate reduces to 80 $\mathrm{m}$. Values of these magnitudes are consistent with the hypothesis that the bulk of the displacement took place undersea.

Figure 12 shows a schematic cross section of the block slide motion of the Kalapana earthquake, together with the hypocenter, aftershock zone, and volcano-crust and crustmantle interfaces. The hypocenter and aftershock depths indicate that the event took place near the estimated location of the volcano-crust interface. However, we make no conclusion as to whether or not the slide plane coincides with this interface. The volcano-crust interface presumably dips gently underneath the island. Although we know that the slide plane is near horizontal, its dip cannot be precisely resolved from either the long-period seismic analysis or the diffuse aftershock area. Once the event developed, there was probably no longer one single slide plane. We envision that the slide block, originally moving on a plane at about $7 \mathrm{~km}$ depth and partially decoupled, loses its

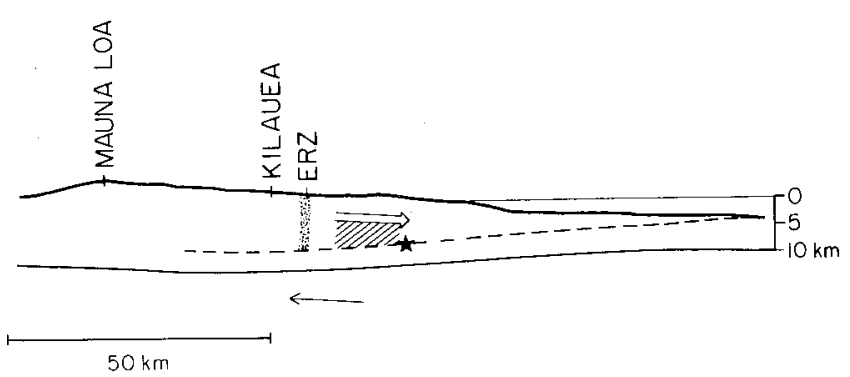

Fig. 12. Schematic cross section of the south flank during the Kalapana earthquake, drawn approximately to scale. Open arrow represents the motion of the upper block; solid arrow is the resultant seismic force. Stipled area represents the east rift zone. Star represents the hypocenter. The aftershock zone (hatchured area) is taken from Crosson and Endo [1982]. Depths to the volcano-crust interface (dashed line) and crust-mantle interface (solid line) are from Crosson and Koyanagi [1979] and Hill [1969].

coherency as a unit and experiences internal failure on many planes, eventually disintegrating into a massive rubble slide or flow to produce a complex and sustained seismic event. Although the entire event may have been initiated by a small tectonic earthquake caused by magmatic stresses, gravity must play a major role in driving this sustained slumping process.

\section{Conclusion}

The observed long-period seismic radiation associated with the Kalapana earthquake can be adequately modeled by assuming a single force for the seismic source as opposed to the double force couple. The force orientation determined by modeling the Love and Rayleigh surface waves is near-horizontal $\left(\alpha \sim 10^{\circ}\right)$ with an azimuth of $330^{\circ}$, opposite to the displacement direction observed on land. The time history of the force inferred from Rayleigh waves has a total duration of about $3 \mathrm{~min}$. The peak force $f_{\circ}$ determined from the surface wave amplitudes is about $1 \mathrm{x}$ $10^{15} \mathrm{~N}$. The force is interpreted to represent seaward slumping of a large massive block of the south flank of Kilauea on a shallow and near-horizontal plane.

The single-force slumping model explains some observations of the Kalapana earthquake that are difficult to reconcile with the double-couple model, such as the observed Love wave amplitude radiation pattern, the large coseismic surface displacements (at least up to and probably greater than $8 \mathrm{~m}$ ), and the large tsunami generated by the event. From geological observations [e.g., Moore, 1964], large-scale slumping off of volcanic slopes is a common mode of deformation for the Hawaiian Ridge. Through application of the single-force model, we have shown that such slumping can generate large seismic events. The single force may be applicable as a source model to some other classes of earthquakes as well, such as massive sediment slides on passive continental margins that are otherwise expected to be zones of low seismicity, or tsunami earthquakes.

Acknowledgments. We thank personnel at the Albuquerque Seismological Laboratory of the U.S. Geological Survey for preparing a tape of HGLP data upon request. Gordon Stewart originally collected the WWSSN records used in this study. We acknowledge conversations with James Moore and Richard Fiske and useful criticism by the JGR reviewers. This research was supported by National Science Foundation grants EAR-8313223, Earth Sciences 
Section, and ECE-8303647, Engineering Section. Contribution 4331, Division of Geological and Planetary Sciences, California Institute of Technology, Pasadena, California.

\section{References}

Ando, M., The Hawaii earthquake of November 29, 1975: Low dip angle faulting due to forceful injection of magma, J. Geophys. Res. 84, 7616-7626, 1979.

Cox, D. C., Source of the tsunami associated with the Kalapana (Hawaii) earthquake of November 1975, Rep. 80-8, 46 pp. Hawaii Inst. of Geophys., Univ. of Hawaii, Honolulu, 1980.

Crosson, R. S., and E. T. Endo, Focal mechanisms of earthquakes related to the 29 November 1975 Kalapana, Hawaii earthquake: The effect of structural models, Bull. Seismol. Soc. Am. 71, 713-729, 1981.

Crosson, R. S., and E. T. Endo, Focal mechanisms and locations of earthquakes in the vicinity of the 1975 Kalapana earthquake aftershock zone 1970-1979: Implications for the tectonics of the south flank of Kilavea volcano, Hawaii, Tectonics, 1, 495-542, 1982.

Crosson, R. S., and R. Y. Koyanagi, Seismic velocity structure below the island of Hawaii from local earthquake data, J. Geophys. Res.. 84, 2331-2342, 1979.

Furumoto, A. S., and R. L. Kovach, The Kalapana earthquake of November 29, 1975: An intra-plate earthquake and its relation to geothermal preocesses, Phys. Earth Planet. Inter. 18, 197-208, 1979.

Hatori, T., Wave source of the Hawaii tsunami in 1975 and the tsunami behavior in Japan (in Japanese), Zisin. 2(29), 355-363, 1976.

Heezen, B. C., and C. L. Drake, Grand Banks slump, Geological Notes, Am. Assoc. Pet.Geol. Bull. 48, 221-225, 1964.

Heezen, B. C., and M. Ewing, Turbidity currents and submarine slumps, and the 1929 Grand Banks earthquake, Am. J. Sci., 250, 849-873, 1952.

Hill, D. P., Crustal structure of the island of Hawaii from seismic refraction measurements, Bull. Seismol. Soc. Am. 59, 101-130, 1969.

Kanamori, H., Synthesis of long-period surface waves and its application to earthquake source studies-Kurile Islands earthquake of October 13, 1963, J. Geophys. Res. 75, 5011-5027, 1970.

Kanamori, H., Mechanism of tsunami earthquakes, Phys. Earth Planet. Inter. 6 346-359, 1972.

Kanamori, H., and J. J. Cipar, Focal process of the great Chilean earthquake May 22, 1960, Phys. Earth Planet. Inter. $\underline{9}, 128-136,1974$.

Kanamori, H., and J. W. Given, Use of long-period surface waves for rapid determination of earthquake source parameters, Phys. Earth Planet. Inter., 27, 8-31, 1981.
Kanamori, H., and J. W. Given, Analysis of long-period seismic waves excited by the May 18, 1980 eruption of Mount St. Helens-A terrestial monopole?, J. Geophys. Res., 87, 5422-5432, 1982.

Kanamori, H., J. W. Given, and T. Lay, Analysis of seismic body waves excited by the Mount St. Helens eruption of May 18, 1980, J.Geophys. Res.. 89, 1856-1866, 1984.

Lipman, P. W., J. P. Lockwood, R. T. Okamura, D. A. Swanson, and K. M. Yamashita, Ground deformation associated with the 1975 magnitude-7.2 earthquake and resulting changes in activity of Kilauea volcano, Hawaii, U.S. Geol. Surv. Prof. Pap., 1276, 45 pp., 1985.

Macdonald, G. A., A. T. Abbot, and F. L. Peterson, Volcanoes in the Sea, 2nd ed. 517 pp., University of Hawaii Press, Honolulu, 1983

Moore, J. G., Giant submarine landslides on the Hawaiian Ridge, U.S. Geol. Surv. Prof. Pap. 501-D, D95-D98, 1964.

Moore, J. G., and D. L. Peck, Bathymetric, topographic, and structural map of the south-central flank of Kilauea volcano, Hawaii, U.S. Geol. Surv. Misc. Geol. Invest. Map, I-456, 1965.

Nakamura, K., Why do long rift zones develop in Hawaiian volcanoes (in Japanese), Kazan. 25, 255-269, 1980.

Rojahn, C., and B. J. Morrill, The Island of Hawaii earthquakes of November 29, 1975: Strong-motion data and damage reconnaissance report, Bull. Seismol. Soc. Am. 2 493-515, 1977.

Sipkin, S. A., Interpretation of non-double-couple earthquake mechanisms derived from moment tensor inversion, J. Geophys. Res., 91, 531-547, 1986.

Swanson, D. A., W. A. Duffield, and R. S. Fiske, Displacement of the south flank of Kilauea volcano: The result of forceful intrusion of magma into the rift zones, U.S. Geol. Surv. Prof. Pap. 963, 39 pp., 1976.

Tilling, R. I., R. Y. Koyanagi, P. W. Lipman, J. P. Lockwood, J. G. Moore, and D. A. Swanson, Earthquake and related catastrophic events, Island of Hawaii, November 29, 1975: A preliminary report, U.S. Geol. Surv. Circ. $\underline{740} 33$ pp., 1976.

H. K. Eissler, Institute of Geophysics and Planetary Physics, Scripps Institution of Oceanography, University of California, San Diego, La Jolla, CA 92093.

H. Kanamori, Seismological Laboratory, California Institute of Technology, Pasadena, CA 91125.

(Received August 4, 1986; revised December 9, 1986; accepted December 18, 1986.) 